\title{
THE ABSORPTION OF TRI-ORTHO-CRESYL PHOSPHATE THROUGH THE SKIN OF HENS AND ITS NEUROTOXIC EFFECTS
}

\author{
BY
}

\author{
P. GLEES and W. G. WHITE \\ From the University Laboratory of Physiology, Oxford
}

General and neurotoxic effects of ingested triortho-cresyl phosphate *(TOCP) in man and animals have been described in detail for the last 20 years. We refer here only briefly to the clinical literature where TOCP was implicated, such as Jamaica ginger paralysis in America (Aring, Bean, Roseman, Rosenbaum, and Spies, 1941; Aring, 1942); the massive intoxications by engine oil at the beginning of the Second World War in Germany (Creutzfeldt and Orzechowski, 1941-43), in Switzerland (Moeschlin, 1952), and recently in Morocco (Smith and Spalding, 1959). Experiments on animals to study the dosage and the histology have been carried out by Barnes and Denz (1953), Cavanagh (1954), Hierholzer, Noetzel, and Schmidt (1957), Glees (1957), Silver (1959), Bondy, Field, Worden, and Hughes (1960), and Glees and White (1960). While these studies have clarified the amounts of TOCP necessary for producing toxic effects, little attention has been paid to the possibility that TOCP might be absorbed by the skin so readily that it would also damage the central nervous system. The likelihood of TOCP coming in contact with the skin in industrial workers is great as it is contained in small amounts in some plasticisers, lubricants, and petrol additives, as well as in certain lacquers. That skin absorption is possible was demonstrated by Hodge and Sterner (1943) using radio-active TOCP compounds. We decided therefore to study in a systematic way the amount of TOCP to be painted on the skin of hens necessary to cause symptoms, and to investigate neurohistologically the degree of nerve fibre degeneration.

\section{Methods of TOCP Administration}

Pure TOCP was painted on the combs of $\mathbf{3 2}$ mature hens and cocks, ranging from 3 to $5 \mathrm{~kg}$. in weight, with the help of a tuberculin syringe, bringing the nozzle in direct contact with the comb. In a single session $0.2 \mathrm{ml}$. could be spread on this skin, and an interval of one day

*Tri-ortho cresyl phosphate is also known as tri-ortho-tolyl phosphate. was observed for additional paintings. In eight hens, oral doses of TOCP, varying from $0.1 \mathrm{ml} . / \mathrm{kg}$. to $0.3 \mathrm{ml} . / \mathrm{kg}$., were administered, to compare their effects with the cutaneous application.

After an initial trial period, when we used varying quantities of the substance, we soon found that $\mathbf{0} \cdot 1-0 \cdot 2$ $\mathrm{ml}$. TOCP $/ \mathrm{kg}$. painted on the comb regularly produced functional and neuropathological signs of intoxication and $0.05 \mathrm{ml}$. TOCP $/ \mathrm{kg}$. produced neuropathological damage only.

\section{Clinical Signs}

A few days after TOCP had been applied the chicken showed a decrease in appetite lasting several days before returning to normal. The loss of appetite is followed by a characteristic head shaking, which comes in bursts lasting several minutes. On the average, 15-20 days after painting, the hen is found sitting down but can get up when prodded. At the same time the appetite is again greatly reduced or abolished. The gait becomes stepping, and the hen is incapable of a balanced posture. Closer examination shows that the extensors of the toes are mainly involved. The toes are held in a typical claw-like position while the flexors, when tested by extending individual toes, are very strong. When the bird is thrown into the air it can fly very skilfully, and the tail and wings fan out in the appropriate way to facilitate landing. However, as the toes do not spread out due to weakness of the extensors, the bird falls over. The head is held erect throughout the illness and the bird follows visual stimuli attentively and reacts normally to sound. The exertion of flying causes the bird to breathe unduly heavily. After a dose of $0.2 \mathrm{ml}$. of TOCP or more, the paralysis will eventually be followed by a respiratory failure, which is instrumental in bringing about the death of the animal, unless a cortisone preparation is given (Glees, 1960).

\section{Neurohistological Techniques}

The animals were, after varying intervals, deeply anaesthetized with nembutal and perfused with formol saline. The extent of perfusion necessary for good fixation can be judged from the appearance of the comb, which becomes quite pale, and the stiffness of neck and legs. Waiting for an hour after perfusion the central nervous system and the peripheral nerves were dissected 
carefully and suitable levels immersed in Marchi (SwankDavenport modification) fluid. The blocks selected for silver stains were fixed for a further week. The silver impregnation methods of Glees and Nauta (1955) were used.

\section{Neurohistological Findings}

In order to avoid a repetitive account of the histology, we have selected from our material three hens, Nos. 28, 51, and 42.

Hen 28: 0.05 ml. TOCP/kg. - The hen painted with a total dose of $0.2 \mathrm{ml}$. (body weight $4.1 \mathrm{~kg}$.), survived 53 days, and did not show signs of intoxication at any time. Marchi preparations of transverse sections of the spinal cord show a moderate degree of degenerating fibres in the ventromedial area of the cord, and longitudinal sections of this region demonstrate the breaking up of the myelin into large and small droplets (Figs. 1 and 2). Medullary levels show a similar small involvement of the spinocerebellar tract.

Hen 51 : $0 \cdot 1 \mathrm{ml}$. TOCP $/ \mathrm{kg}$.- The total dose given was $0.37 \mathrm{ml}$. (body weight $3.7 \mathrm{~kg}$.). The hen was badly paralysed after 13 days and was killed 26 days

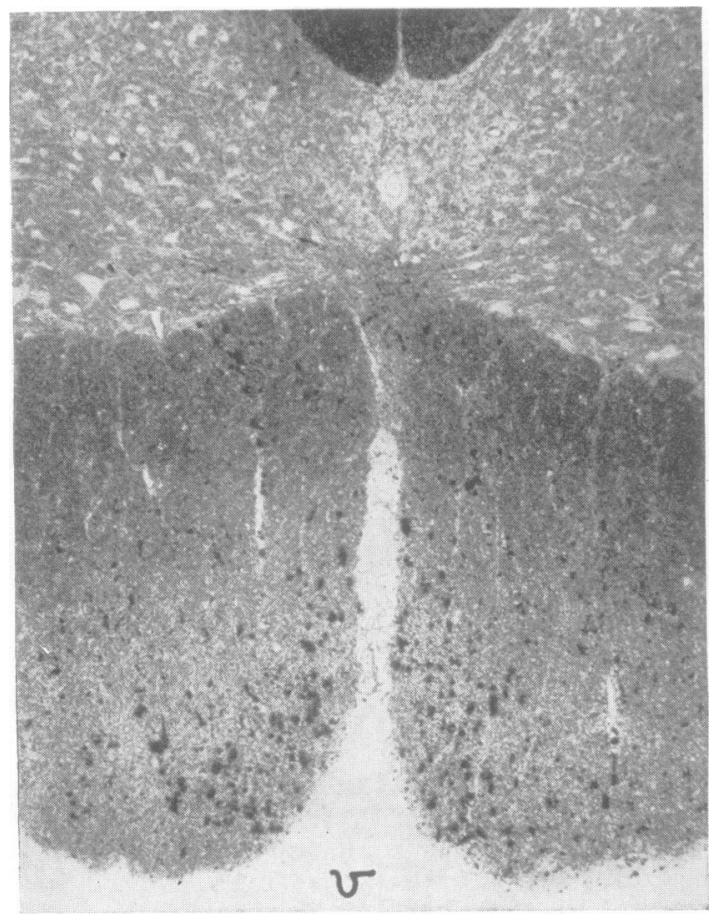

Fig. 1.-Hen 28. Transverse section through lumbar cord. $\mathrm{V}=$ ventral. On either side of the ventro-medial fissure myelin degeneration can be seen (Marchi $\times 35$ ). after painting. The slides of lumbar and medullaryㅡㅡㅁ levels show a considerable area of degeneration $z$ (Fig. 3). Hens which had $0.2 \mathrm{ml} . / \mathrm{kg}$. or more show异 a further increase in degeneration both in Marchio and in silver preparations.

All chickens who have a positive Marchi staining show, when impregnated with the Nauta and Gleeses technique, disintegrating axones (see Fig. 4), confirming Cavanagh's findings (1954). In addition to axonal changes very distinct synaptic degeneration $\vec{z}$ was found in a circumscribed area of the grey matter $\vec{\Rightarrow}$ (Glees, 1961).

Glial reactions become obvious only in the latero stages of degeneration and appear to be secondary to axone fragmentation (Fig. 5). This is clearly seen $\frac{\bar{\rho}}{\bar{C}}$ in hen 42 (body weight $3.4 \mathrm{~kg}$.) which was given $0.7 \mathrm{ml}$. TOCP and killed 55 days later.

\section{Discussion}

Cutaneous application of TOCP, $0 \cdot 1 \mathrm{ml}$. or more, $\overrightarrow{\vec{\omega}}$ causes in hens a characteristic clinical and neuro- $\rho$ pathological picture. The latter is limited to as selected area of the cord and peripheral nerves are not involved. This clearly demonstrates that pure TOCP can penetrate through the skin of the combi

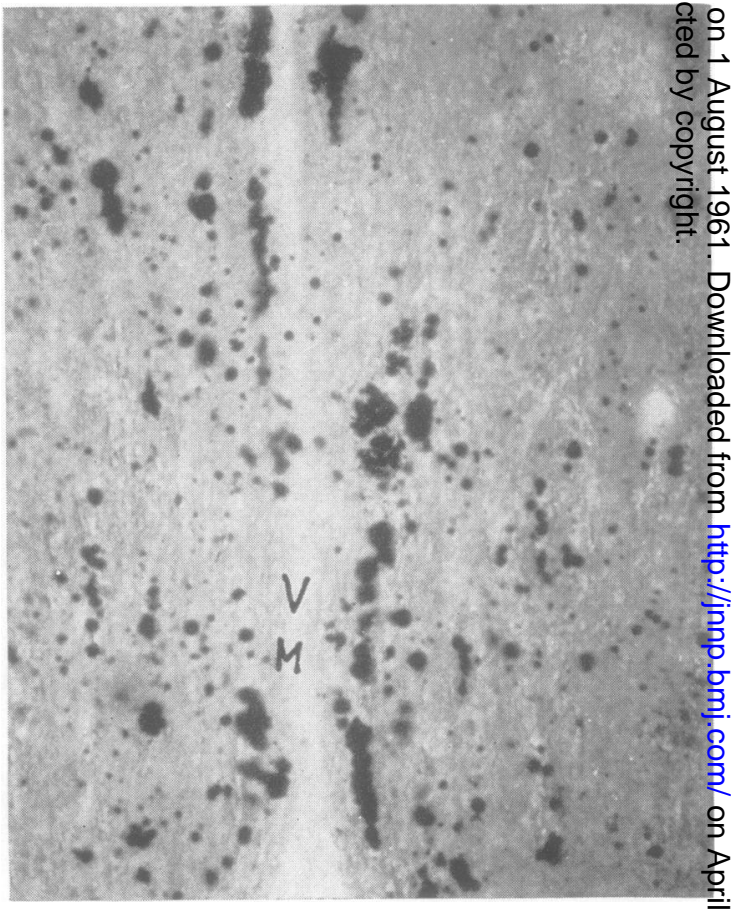

FIg. 2.-Hen 28. Longitudinal section of lumbar cord. V.M. $=$ ventro-medial fissure (compare with Fig. 1). Large myelinated fibres are shown in the process of disintegration $($ Marchi $\times 420)$
ڤ)

\section{$\vec{\circ}$}




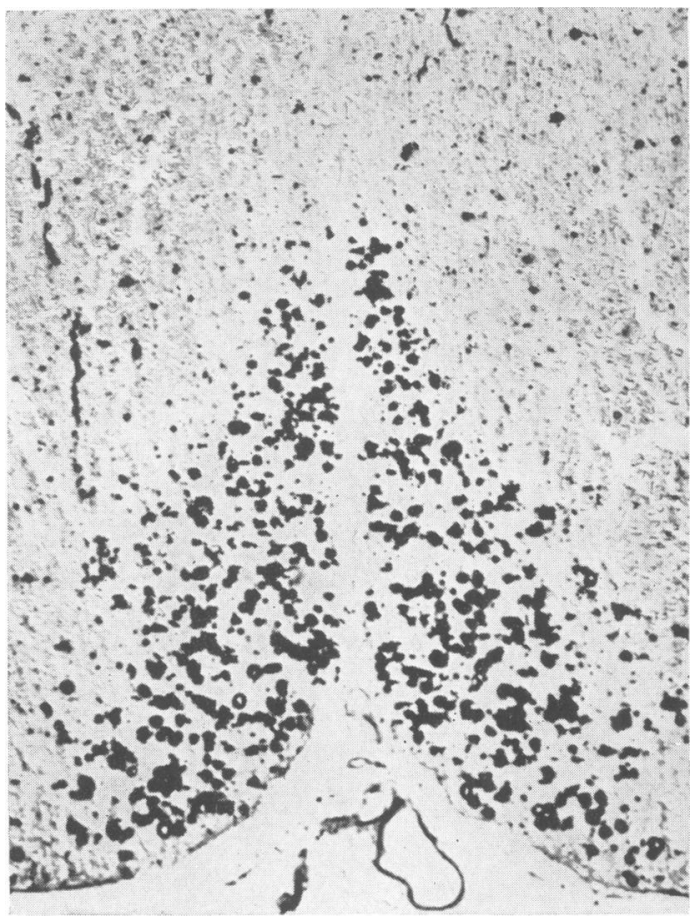

FIG. 3.-Hen 51. The Marchi degeneration at lumbar level on either side of the ventromedial fissure is much more pronounced than in the case of hen 28 (Marchi $\times 100)$.

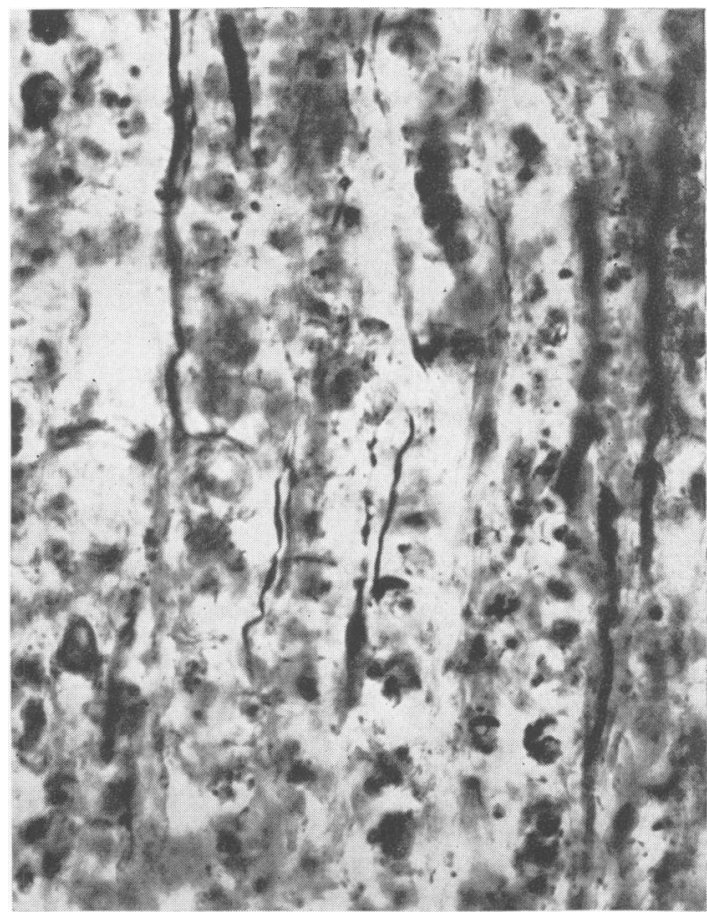

Fig. 4.-Hen 35. Longitudinal section through the ventromedial area of the spinal cord, lumbar level. Note the disintegration and fragmentation of axones (Nauta $\times 420$ ).

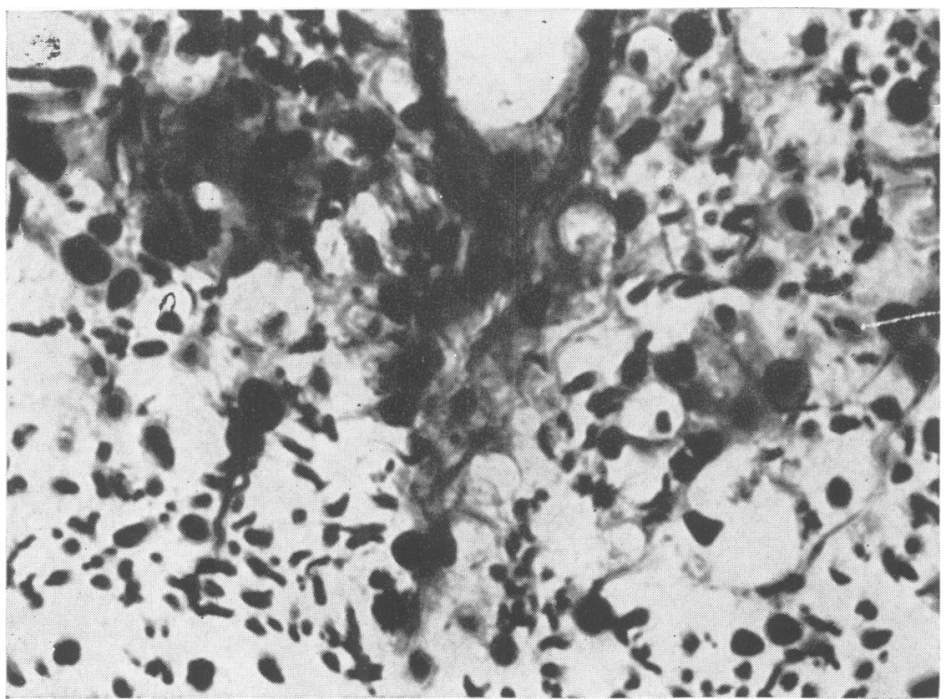

FIG. 5.-Hen 42. Section of ventromedial portion of lumbar cord showing glial proliferation (right side of picture), also myelin and axone degeneration (left side of the picture shows normal axones) (Glees $\times 420$ ). 
producing a similar disease to that which has been described for TOCP taken by mouth. The fact that TOCP can be absorbed rapidly by the skin has been shown by radioactive TOCP applied to the skin and its excretion by the kidney measured by the GeigerMuller counter (Hodge and Sterner, 1943). These authors were surprised by the rapidity and quantity of absorption, which reached high values after one hour. Doses as small as $0.05 \mathrm{ml} . / \mathrm{kg}$. are still capable of causing tract degeneration in the cord although no functional abnormalities could be observed. As TOCP is retained in the tissues (visceral organs and brain) (Hodge and Sterner, 1943), it is possible that the continuation of such a small dose of TOCP as $0.05 \mathrm{ml}$. might result in an obvious state of toxicity.

\section{Summary}

Functional and neurohistological studies in 40 chickens painted on the comb with $0 \cdot 1 \mathrm{ml}$. TOCP $/ \mathrm{kg}$. or more show a characteristic paralysis of leg extensors and selected spinal tract degeneration of both myelin and axone.

Even a single dose of $0.05 \mathrm{ml}$. TOCP $/ \mathrm{kg}$. is capable of causing a small amount of nerve fibre degeneration in the anterior medial tract of the cord.
No degeneration of peripheral nerves of the leg was detected with the dosage used.

We would like to thank Mr. P. P. Hopf, B.Sc., for the supply of pure TOCP and his interest in this problem, anc Mrs. M. Krebs, B.Sc., M.Sc., Miss F. Greene, Mr. Bo Sheppard and Mr. H. Hauffe, B.A., for technicad assistance. This investigation was partly supported bo grant No. 259 from the National Multiple Sclerosie Society, and partly by a grant from Messrs. A. Boake Roberts and Co., Ltd., and the Geigy Co. Ltd.

\section{REFERENCES}

Aring, C. D. (1942). Brain, 65, 34.

Bean, W. B., Roseman, E., Rosenbaum, M., and Spies, T. D (1941). Arch. Neurol. Psychiat. (Chicago), 45, 772.

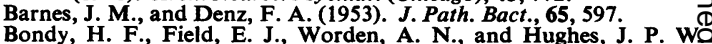
(1960). Brit. J. industr. Med. 17, 190.

Cavanagh, J. B. (1954). J. Neurol. Neurosurg. Psychiat., 17, 163

Creutzfeldt, H. G., and Orzechowski, G. (1941-43). Fühner's SammL Vergiftungsf., 12, 147.

Glees, P. (1957). Morphologie und Physiologie des Nervensystems. Thieme, Stuttgart.

(1960). Nature (Lond.), 187, 327

(1961). Dtsch. med. Wschr. 86, 1175.

and Nauta W. J. H. (1955). Mschr. Psychiat Neurol. 129, 74

, and White, W. G. (1960). J. Physiol. (Lond.), 153, 20P.
Hierholzer, K., Noetzel, H., and Schmidt, L. (1957). Arzeimitteto Forsch., 7,585 . H., and Schmidt, L. (1957). Arzneimittelo

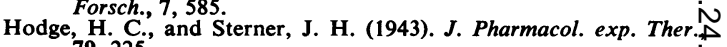
79, 225 .'

Moeschlin, S. (1952). Klinik und Therapie der Vergiftungen. Thienfe $\omega$ Stuttgart.

Silver, A. (1959). J. Physiol. (Lond.), 148, 66P.

Smith, H. V., and Spalding, J. M. K. (1959). Lancet, 2, 1019. 